\title{
Immobilization of cytochrome $c$ on cysteamine-modified gold electrodes with EDC as coupling agent
}

\author{
Karolien De Wael ${ }^{\mathrm{a}, 1}$, Hans Buschop ${ }^{\mathrm{a}}$, Lina De Smet ${ }^{\mathrm{b}}$, Annemie Adriaens ${ }^{\mathrm{a}, *}$ \\ a Ghent University, Department of Analytical Chemistry, Krijgslaan 281 S12, B-9000 Ghent, Belgium \\ ${ }^{\mathrm{b}}$ Ghent University, Department of Biochemistry, Physiology and Microbiology, KL Ledeganckstraat 35, B-9000 Ghent, Belgium
}

\section{A R T I C L E I N F O}

Article history:

Received 12 December 2007

Received in revised form 19 February 2008

Accepted 26 February 2008

Available online 4 March 2008

\section{Keywords:}

Cytochrome $c$

Carbodiimide coupling

EDC

Cross-linking

Film

Voltammetry

Cysteamine

\begin{abstract}
A B S T R A C T
Cyclic voltammetry has been applied for the characterization of cross-linked horse heart cytochrome $c$ (HHC) on cysteamine-modified gold electrodes. The cross-linking, i.e. amide bond formation, between the proteins was achieved by using 1-ethyl-3-(3-dimethylaminopropyl)-carbodiimide (EDC) as coupling reagent. The optimal conditions for the formation of the HHC film were determined by varying the HHC concentration. In addition the reproducibility, stability and the influence of the scan rate upon these films were investigated with cyclic voltammetry. The protein film stability in a 4-(2-hydroxyethyl)-1piperazineethanesulfonic acid (HEPES) buffer solution was tested by UV/vis absorption spectroscopy.
\end{abstract}

(C) 2008 Elsevier B.V. All rights reserved.

\section{Introduction}

Immobilization of direct electrochemistry of redox proteins on electrodes can provide insight into the electron transfer processes between proteins in real biological systems [1,2]. Apart from this redox-active proteins are potentially useful in the development and fabrication of new kinds of biosensors or bioreactors $[3,4]$. Such studies can be performed by the so-called "protein film voltammetry", founded by Armstrong et al. [5], in which proteins are either incorporated into various films [6,7] or in which they are crosslinked to each other to form a film. Different types of films occur, including insoluble surfactants $[8]$, hydrogel polymers $[9,10]$ and mesoporous oxide films [11]. They all facilitate the electron transfer between the proteins and the electrode $[12,13]$.

The cross-linking approach of proteins, under investigation in this work, generally leads to the formation of protein films with properties of a hydrogel. The latter are polymeric materials which exhibit the ability to swell in an aqueous solution without dissolving in it [14]. Two kinds of hydrogels can be distinguished: chemically and physically cross-linked hydrogels. The difference

\footnotetext{
* Corresponding author. Tel.: +32 926448 26; fax: +32 92644960 .

E-mail address: Annemie.Adriaens@UGent.be (A. Adriaens).

1 Postdoctoral Fellow of the Research Foundation - Flanders, Belgium.
}

between both types is the nature of the cross-link points or junctions: it is either a chemical bond or a physical interaction. In the case of the latter, ionic interactions, hydrophobic associations or coiled-coil interactions appear [15-17]. When covalent bondings are incorporated in the hydrogel, a tight and stable film is formed. To achieve the latter, commonly carbodiimides are used which couple carboxyls to primary amines resulting in the formation of amide bondings. Seminal work in this field using cytochrome $c$ as redox protein was published by Collison et al. [18]. In the presence of excess cross-linker, polymerization can occur because all proteins contain carboxyls and amines. In this work, 1-ethyl-3-(3-dimethylaminopropyl)-carbodiimide (EDC) was used as a cross-linking agent. It reacts with carboxylic acids to create an active-ester intermediate. In the presence of an amine nucleophile, an amide bond is formed with the release of an isourea byproduct.

Horse heart cytochrome $c(\mathrm{HHC})$ is a redox protein which has been mostly studied with respect to direct protein electrochemistry (see $[2,4,19]$ and references therein). It is an important hemecontaining metalloprotein which functions as an electron carrier. This redox protein has often been considered as a model system for biological electron transfer [20] and for bioelectrocatalysis [21].

In this paper (part I of our study), we report on the formation of a HHC film, cross-linked by 1-ethyl-3-(3-dimethylaminopropyl)carbodiimide, on a cysteamine-modified gold electrode surface. 
The optimal conditions for the formation of the HHC thin-film were determined by varying the HHC concentration. The reproducibility, stability and the influence of the scan rate upon the HCC film were investigated with cyclic voltammetry. The protein film stability in a 4-(2-hydroxyethyl)-1-piperazineethanesulfonic acid (HEPES) buffer solution was tested by UV/vis absorption spectroscopy.

\section{Experimental}

\subsection{Reagents}

Horse heart cytochrome $c$, 2-[4-(2-hydroxyethyl)-piperazinyl] ethanesulfonic acid, cysteamine (CYS), sodium hydroxide, sodium dithionite and 1-ethyl-3-(3-dimethylaminopropyl)-carbodiimide were purchased from Sigma-Aldrich. The HEPES buffer solution of $10 \times 10^{-3} \mathrm{~mol} \mathrm{~L}^{-1}$ was set to $\mathrm{pH} 7.0$ using a $0.15 \mathrm{~mol} \mathrm{~L}^{-1} \mathrm{NaOH}$ solution.

\subsection{Preparation of the modified electrodes}

Prior to their first use the gold electrode surfaces, having a diameter of $1.6 \mathrm{~mm}$ (BASinstruments, West Lafayette, USA), were scoured briefly on SiC-emery paper 1200 grit to obtain an active surface. To smoothen this relatively rough surface, it was further subjected to sequential polishing using a cloth covered with alumina powder (Buehler, Illinois, USA) of $1,0.3$ and $0.05 \mu \mathrm{m}$ particle size for, respectively, 5, 10 and $20 \mathrm{~min}$. To remove any adherent $\mathrm{Al}_{2} \mathrm{O}_{3}$ particles, the electrode surface was rinsed thoroughly with doubly deionized water and cleaned in an ultrasonic bath (Branson 3210) for $2 \mathrm{~min}$.

After being rinsed with water and dried with a nitrogen gas flow, the gold electrodes were incubated in a water solution containing $5 \mathrm{mmol} \mathrm{L}^{-1}$ cysteamine (CYS) for $24 \mathrm{~h}$ at room temperature, which allowed the adsorption of CYS onto the surface. The modified gold electrodes were rinsed with water to remove any physically adsorbed CYS. In what follows, these modified electrodes are denoted as CYS $\mid \mathrm{Au}$ in the text. To immobilize horse heart cytochrome $c$ (HHC) onto CYS|Au, $15 \mu \mathrm{L}$ of a HHC containing buffer solution (different concentrations: see further) and $5 \mu \mathrm{L}$ of a $2.5 \mathrm{~mol} \mathrm{~L}^{-1}$ EDC solution were spread onto the surface using a Hamilton syringe and exposed to the air for $2 \mathrm{~h}$ at room temperature. The formation of the film occurred while the aqueous phase dried. Finally, these electrodes were washed with the HEPES buffer solution. This electrode is referred to in the text as $\mathrm{HHC}|\mathrm{EDC}| \mathrm{CYS} \mid \mathrm{Au}$. Important to note is that in order to obtain the typically red coloured HHC film on the electrode surface, it was necessary to expose HHC and EDC to air during the cross-linking process. The latter implied the absence of a cap on top of the electrode so that the buffer solution is able to evaporate out of the formed hydrogel.

\subsection{Electrochemical measurements}

The basic electrochemical setup consisted of a three-electrode cell using a saturated calomel reference electrode (SCE, $E=0.244 \mathrm{~V}$ vs. NHE at $298 \mathrm{~K}$, Radiometer, Copenhagen) and a platinum counter electrode. Voltammetry measurements were performed by placing a $20 \mu \mathrm{L}$ buffer droplet between the tip of the reference electrode and the horizontal working electrode disk (modified from Hagen [21]). A PGSTAT20 potentiostat (ECO Chemie, The Netherlands), controlled by the GPES 4.9005 software package (ECO Chemie, The Netherlands) running on a Pentium II computer, was used to record the voltammetric curves.

\subsection{UV/vis measurements}

Droplets of the electrochemical experiment were diluted to $20 \mu \mathrm{L}$. Absorption spectra of the droplets were recorded using a double beam spectrophotometer (Kontron Uvikon, UK) in the absence and the presence of a few crystals of sodium dithionite. By adding the latter, the native (oxidized) form of cytochrome $c$ (ferricytochrome $c$ ) reduces. The concentration of horse heart cytochrome $c$ was determined at $554 \mathrm{~nm}$ by deducting the signal of ferricytochrome $c$ from the signal of the reduced form (ferrocytochrome $c$ ). The molar absorption coefficient for the difference between the reduced and oxidized form of cytochrome $c$ is $21,400 \mathrm{~mol}^{-1} \mathrm{~L} \mathrm{~cm}^{-1}[22]$.

\section{Results and discussion}

In a first experiment the influence of CYS on the direct electrochemistry was investigated. For this two electrodes were prepared: the first one consisted of depositing $15 \mu \mathrm{L} 3.75 \mathrm{mmol} \mathrm{L}^{-1} \mathrm{HHC}$ and $5 \mu \mathrm{L} 2.5 \mathrm{~mol} \mathrm{~L}^{-1}$ EDC onto a bare gold electrode surface. The second one was first pre-treated with $5 \mathrm{mmol} \mathrm{L}^{-1} \mathrm{CYS}$, according to the procedure listed in Section 2, in order to obtain a more hydrophilic and thus a more accessible surface. After that HCC and EDC were deposited in an identical procedure as for the first electrode.

Fig. 1 shows the cyclic voltammetric behaviour of a HHC (3.75 $\left.\mathrm{mmol} \mathrm{L}^{-1}\right) \mid$ EDC film immobilized on a bare gold (dotted line) and on a CYS|Au electrode (solid line). In both cases protein film formation can be observed: the observed redox couple can be explained as the oxidation and the reduction of the heme group in the protein. The midpoint potential of the observed process $\left(E_{1 / 2, \mathrm{ox}}=0.16 \mathrm{~V}\right.$ vs. SCE $)$ is more positive than the redox potential of native $\mathrm{HHC}\left(E_{1 / 2, \mathrm{ox}}=0.046 \mathrm{~V}\right.$ vs. SCE) $[23,24]$. This potential shift towards more positive values reflects mainly the change of heme environment caused by a changed dielectric constant and a variation of solvation properties and can be primarily attributed to

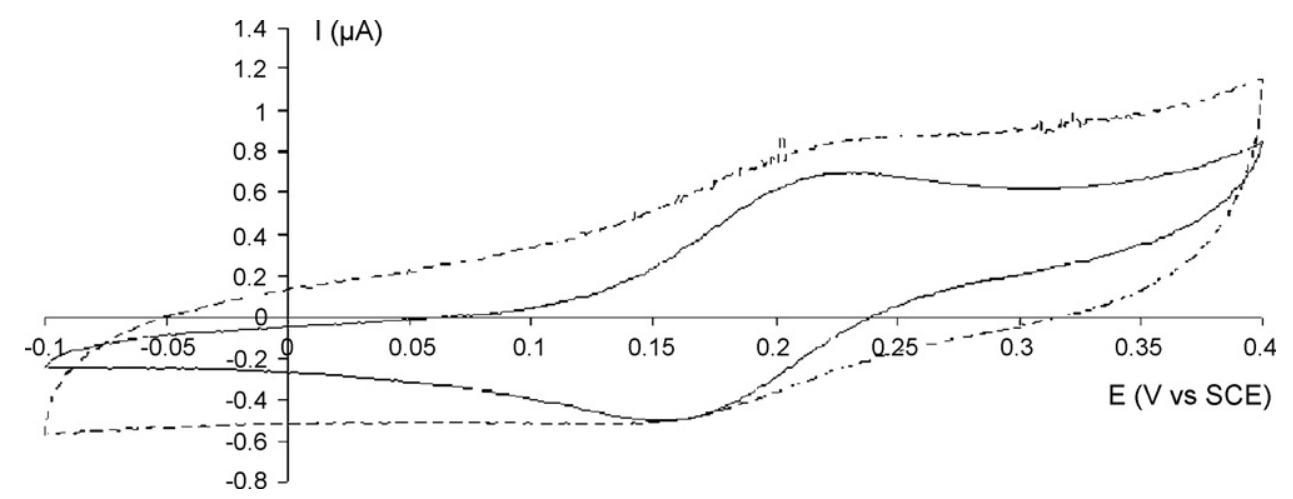

Fig. 1. Current-potential behaviour of a HCC $\left(3.75 \mathrm{mmol} \mathrm{L}^{-1}\right) \mid$ EDC film immobilized on a bare gold (dotted line) and a CYS|Au electrode (solid line). 
the covalent bonding between the HHC molecules because of the presence of EDC $[25,26]$. The latter is responsible for an intermolecular covalent amide bonding. The potential is thus determined by the composition of the adsorbed layer. When the layer would contain the monomeric, native form of HHC, reversible electron exchange can occur. In this situation, the apparent reversibility decreased since the surface was partially covered with polymeric species which can only be oxidized at higher potentials.

The electrochemistry of HHC is governed by the interactions among the protein molecules [26]. Fig. 1 clearly demonstrates that the presence of CYS as an extra linker between the HHC film and the gold electrode causes a more stable background curve. Without CYS, there is no covalent coupling between the gold electrode and the protein film but a redox couple is observed. One can speak of only a physical adsorption of the protein film onto the electrode. Even in the absence of specific interaction or a covalent bond between the protein film and the electrode, the typical electrochemical behaviour of the HHC film is observed. Therefore, and to proof this statement, the use of other electrodes as carrier materials was also investigated. Because HHC has a global positive charge [27], carbon electrodes, which contain negative end groups, were not pre-treated expecting a good interaction between the electrode and the protein film. Indeed, film formation and the typical electrochemical behaviour occurred but the background current was again quite high and the reproducibility was very small. The same could be stated for platinum electrodes. Probably, the lack of a covalent interaction between the protein film and the electrode causes this and makes these bare electrodes not useful as a carrier material.

The amino groups of CYS can react with the HHC molecules through EDC as a coupling agent resulting in a protein film which is covalently adsorbed onto the electrode. It can be stated that CYS facilitates the electron transfer between the electrode and the protein film resulting in a lower background curve. Therefore, only CYS-modified gold electrodes were investigated further.

\subsection{Optimization of the modification procedure}

In search of the optimal conditions for the creation of a crosslinked HHC film on a gold electrode, the HHC concentration was varied. The concentration study showed us that a minimum HHC concentration of $1.5 \mathrm{mmol} \mathrm{L}^{-1}$ is necessary to obtain a HHC film on the electrode. If the concentration of HHC is lower than this value, there will be no visible film formation after $2 \mathrm{~h}$ of reaction time between HHC and EDC. This can be explained by the fact that the cytochrome $c$ molecules are too low in number and too far away from each other to give rise to a covalent bonding between the different protein molecules. The only covalent bonding that occurs is the monolayer protein formation between the CYS immobilized onto the gold electrode and the HHC molecules in the droplet. There is no intermolecular HHC coupling. A cyclic voltammogram (not shown) of such a monolayer HHC-modified electrode reveals a charge of $6.5 \times 10^{-8} \mathrm{C}$ for the reduction peak of ferrocytochrome $c$ corresponding to a surface coverage of $3.37 \times 10^{-11} \mathrm{~mol} \mathrm{~cm}^{-2}$ indicating the formation of a monolayer $[28,29]$.

\subsection{Cyclic voltammetry as a function of scan number and scan rate}

A few of the first 20 cyclic voltammetric scans recorded at a HHC ( $\left.3 \mathrm{mmol} \mathrm{L}^{-1}\right)|\mathrm{EDC}| \mathrm{CYS} \mid$ Au electrode in a HEPES buffer solution are shown in Fig. 2. Regarding the oxidation and reduction process of the iron ion of the heme group, a stable cyclic voltammogram is obtained as of scan 1 . Analogous experiments were performed in order to investigate the reproducibility: Fig. 3 shows the cyclic voltammetric behaviour of four independently prepared

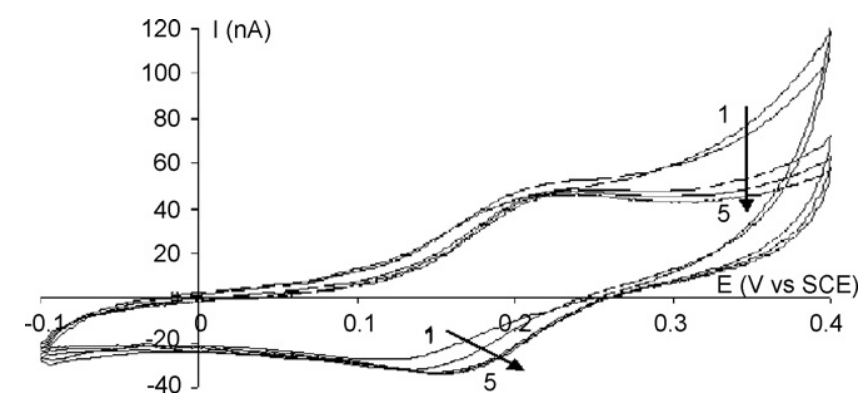

Fig. 2. Successive cyclic voltammograms recorded at a $\mathrm{HCC}\left(3 \mathrm{mmol} \mathrm{L}^{-1}\right)$ EDC $|C Y S| A u$ electrode in a HEPES buffer solution (pH 7): scan \# 1 (1), scan \# 2 (2), scan \# 10 (3), scan \# 15 (4) and san \# 20 (5).

HHC ( $\left.3 \mathrm{mmol} \mathrm{L}^{-1}\right)|\mathrm{EDC}| \mathrm{CYS} \mid \mathrm{Au}$-modified electrodes. The good correlation between these measurements $(\Delta I=2 \mathrm{nA})$ indicates that with this procedure one can create protein-modified electrodes in a very reproducible way.

The influence of the scan rate on the peak current was investigated to determine the nature of the process. Fig. 4a shows the oxidation and reduction of HHC in a HEPES buffer solution over a wide range of scan rates. The oxidation and reduction peak current for HHC, as well as the peak-to-peak separation, increases linearly with the scan rate from 10 till $150 \mathrm{mV} \mathrm{s}^{-1}$. Integration of the area under the peaks gives nearly constant charge values independent of the scan rate, indicating a quasi-reversible surface-confined thinfilm electrochemical behaviour [30]. In the range of explored scan rates, electron diffusion control is observed. Fig. $4 \mathrm{~b}$ shows the relationship between $\log I_{\mathrm{p}}$ and $\log v$. The slope for the redox process is 0.47 , indicating a reaction of a particle in solution. The proteins diffuse into the film in which they are immobilized, and the electron transfer process is achieved by exchange of electrons between the bound proteins. Because of the strong interaction between all proteins, the diffusion layer of in the membrane is much thinner than that in solution (on the same time scale). In theory, complete electrolysis of a thin film of material is expected at very low scan rates. However, for thicker film deposits (and for higher scan rates) diffusion control is observed $[15,30]$. The scan rate for the transition from 'thin-film' behaviour to diffusion characteristics can be predicted by Eq. (1):

$v=\frac{D R T}{\delta^{2} F}$

In this equation the scan rate $v$ for the transition is obtained from the diffusion coefficient $D$, the gas constant $R$, the temperature $T$, the film thickness $\delta$ and the Faraday constant $F$. Knowing that $D_{\text {cytc,membrane }}=2 \times 10^{-14} \mathrm{~m}^{2} \mathrm{~s}^{-1}$ [31], it could be calculated that for a film thickness of ca. $40 \mu \mathrm{m}$, diffusion controlled voltammetric responses are expected. Fig. 5 shows a diagram indicating the char-

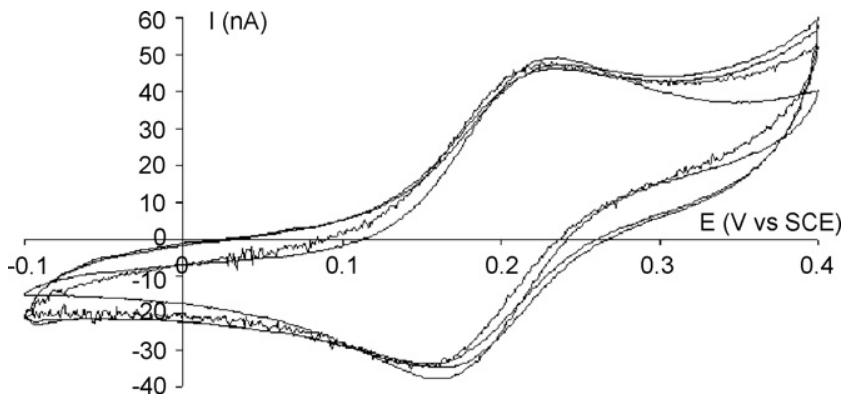

Fig. 3. 20th cyclic voltammogram recorded at four $\mathrm{HCC}\left(3 \mathrm{mmol} \mathrm{L}^{-1}\right)|\mathrm{EDC}| \mathrm{CYS} \mid \mathrm{Au}$ electrodes produced by the same procedure. 

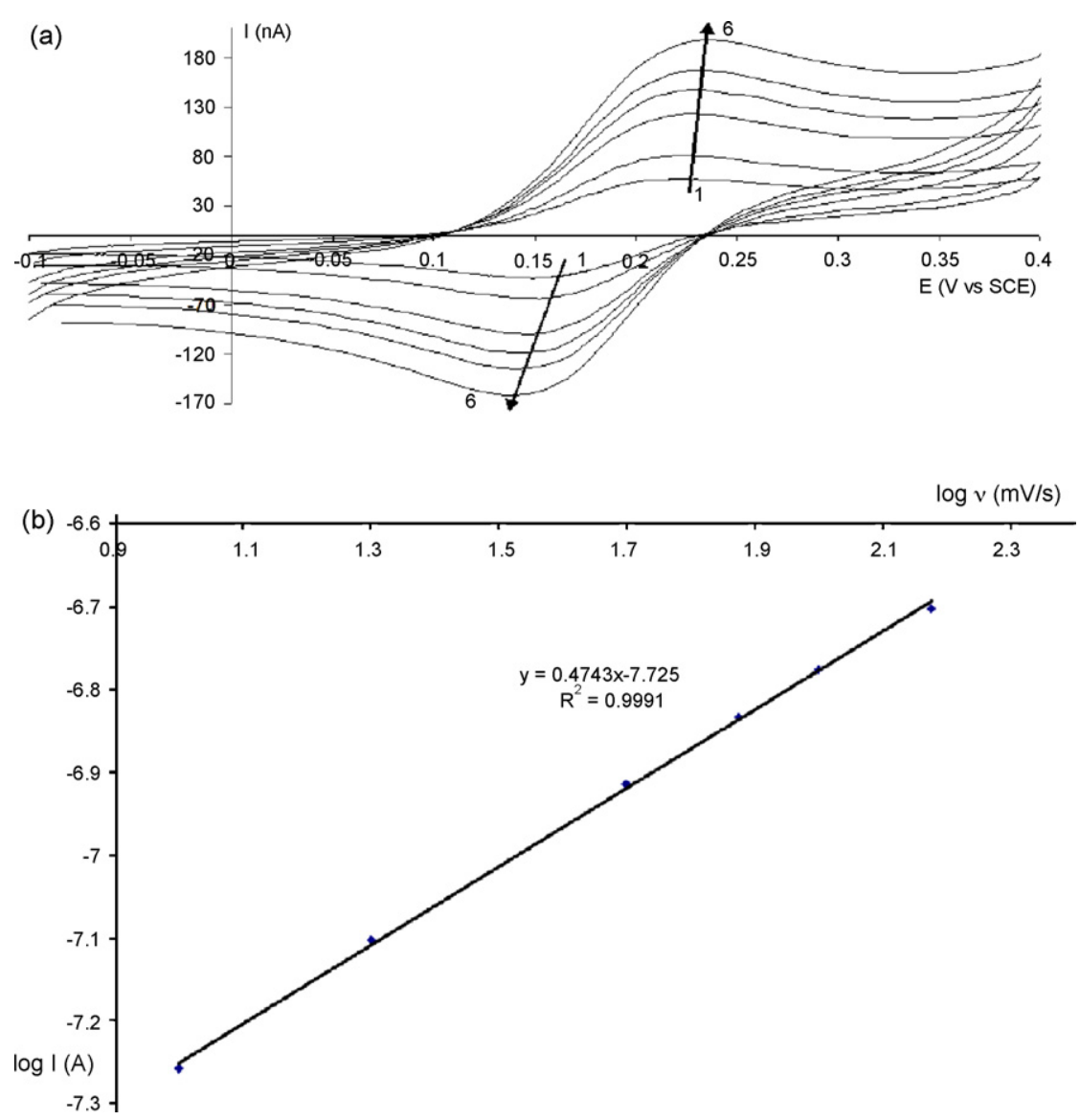

Fig. 4. (a) Current-potential behaviour of a HCC $\left(3 \mathrm{mmol} \mathrm{L}^{-1}\right) \mid$ EDC|CYS|Au electrode in a HEPES buffer solution (pH 7) at different scan rates: 10 (1), 20 (2), 50 (3), 75 (4), 100 (5) and 150 (6) $\mathrm{mV} \mathrm{s}^{-1}$. (b) Relationship between $\log I_{\mathrm{p}}$ and $\log v$.

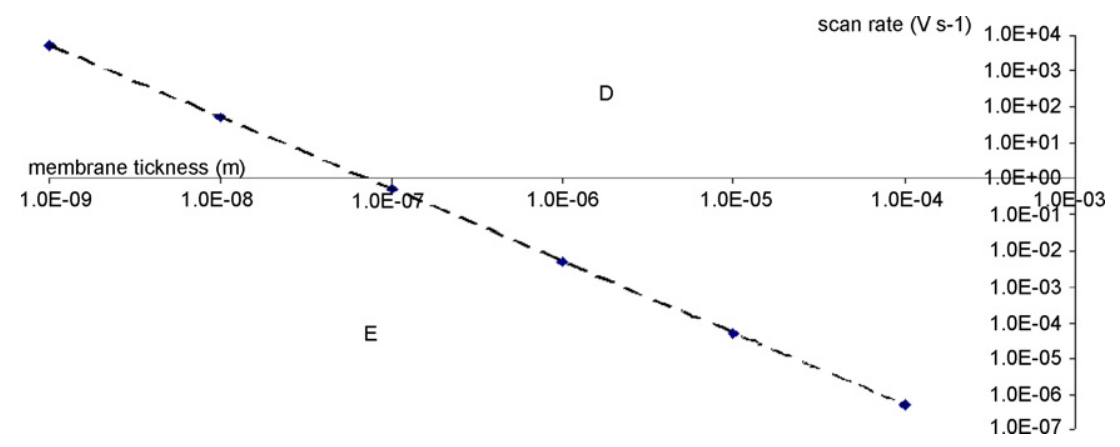

Fig. 5. Plot of the scan rate vs. the membrane thickness (Eq. (1)). The characteristic zones for complete electrolysis (zone E) and for diffusion controlled reactions (zone D) are indicated.

acteristic zones for complete electrolysis (zone E) and for diffusion controlled reactions (zone D) and demonstrates indeed that for film thicknesses of the order of $40 \mu \mathrm{m}$, we are working with diffusion controlled reactions.

\subsection{Stability study}

The protein film stability was tested by storing several HHC ( $3 \mathrm{mmol} \mathrm{L}^{-1}$ )|EDC|CYS $\mid$ Au-modified electrodes in air during several days. Some electrodes were stored at $293 \mathrm{~K}$ and others at $277 \mathrm{~K}$. After returning the dry films to the buffer solution, cyclic voltammograms were recorded after 2 and 7 days. Curve 1 in Fig. 6 represents the initial current-potential behaviour of a HHC $\left(3 \mathrm{mmol} \mathrm{L}^{-1}\right)|\mathrm{EDC}| \mathrm{CYS} \mid \mathrm{Au}$ electrode in a HEPES buffer solution. After 7 days of keeping the electrode at a temperature of $277 \mathrm{~K}$, the

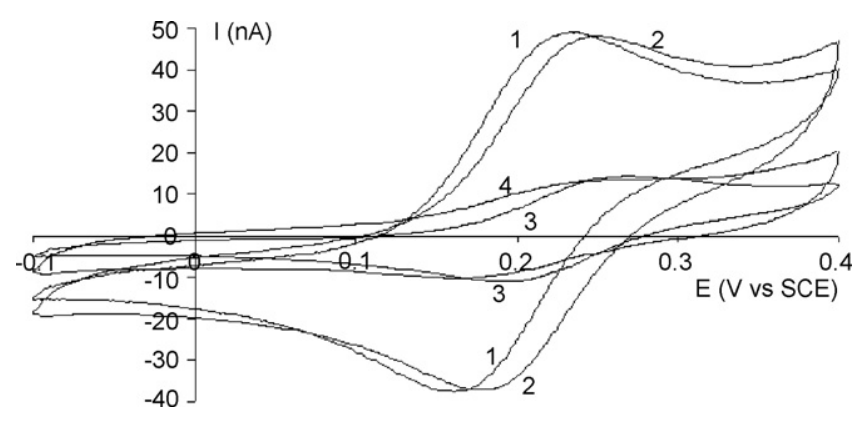

Fig. 6. Current-potential behaviour of a $\mathrm{HCC}\left(3 \mathrm{mmol} \mathrm{L}^{-1}\right)|\mathrm{EDC}| \mathrm{CYS} \mid \mathrm{Au}$ electrode in a HEPES buffer solution ( $\mathrm{pH} 7$ ) after 2 (curve 3 ) or 7 (curve 2,4) days and at room temperature (curve 3,4 ) or at $277 \mathrm{~K}$ (curve 2 ). Curve 1 represents the initial obtained cyclic voltammogram. 
observed cyclic voltammetric behaviour is represented as curve 2 . The peak current and the surface under the peak are quite stable for one week. Only a peak potential shift over ca. $20 \mathrm{mV}$ is observed, probably indicating a small reorganization of the protein film or a change in protein conformation [25].

In contrast, when the electrode was kept at $293 \mathrm{~K}$ for 2 days, an enormous decrease of the peak current is observed (curve 3 ). After 7 days, curve 4 was recorded. Based on these results, it is clear that the modified electrodes should be kept at $277 \mathrm{~K}$ to retain a stable HHC film.

In order to examine whether the protein film is stable in a HEPES buffer solution or during the electrochemical measurements, the droplet of the buffer solution was collected using a syringe after the electrochemical experiment and was further analyzed using UV/vis. The addition of the buffer solution on the protein film during the voltammetric measurement causes a clear expansion of its volume resulting in the formation of a hydrogel. This looser structure of the film may provide a favourable and mainly aqueous microenvironment for transferring electrons with underlying electrodes. The large buffer content of the hydrogel also increases free volume in the film which facilitates diffusion of target molecules into the hydrogel. This phenomenon has possibilities for the development of an enzymatic sensor.

To determine the HHC concentration in a HEPES droplet, sodium dithionite was added to the droplet in order to reduce all HHC. The latter gives a characteristic UV/vis band at $554 \mathrm{~nm}$ [32]. Knowing that its extinction coefficient has a value of $21,400 \mathrm{~mol}^{-1} \mathrm{~L} \mathrm{~cm}^{-1}$, an average concentration of $25 \mu \mathrm{mol} \mathrm{L}^{-1}$, could be calculated in the droplet. The latter implies that only a negligible amount of HHC dissolves in the buffer solution compared to the $3 \mathrm{mmol} \mathrm{L}^{-1} \mathrm{HHC}$ concentration in the film indicating a very stable HHC film. Based on these values, it can be stated that ca. $85 \%$ of the initial amount of HHC forms a cross-linked film. The remaining amount of HHC proteins is not covalently bound to the electrode and dissolves in the HEPES buffer solution after contact.

\section{Conclusion}

The immobilization of a HHC film on a gold electrode, with EDC as coupling agent, has been described in this article. To obtain this protein polymer film, the buffer solution should be able to evaporate out of the hydrogel. It was also observed that the presence of CYS, acting as a covalent linker between the HHC film and the gold electrode, causes a more stable background electrochemical curve. A concentration study showed us that the minimum concentration of HHC to obtain a well-defined protein film is $1.5 \mathrm{mmol} \mathrm{L}^{-1}$. The stability study made clear that the electrodes stored at $277 \mathrm{~K}$ were quite stable in comparison to the ones stored at room temperature.

\section{References}

[1] M.F. Chaplin, C. Bucke, Enzyme Technology, Cambridge University Press, Cambridge, UK, 1990.

[2] F.A. Armstrong, G.S. Wilson, Electrochim. Acta 45 (2000) 2623.

[3] D.R. Thevenot, K. Toth, R.A. Durst, G.S. Wilson, Biosens. Bioelectron. 16 (2001) 121.

[4] Y. Wu, S. Hu, Microchim. Acta 159 (2007) 1.

[5] F.A. Armstrong, H.A. Heering, J. Hirst, Chem. Soc. Rev. 26 (1997) 169.

[6] J.F. Rusling, Acc. Chem. Res. 31 (1998) 363.

[7] N. Hu, Pure Appl. Chem. 73 (2001) 1979.

[8] J. Yang, N. Hu, Bioelectrochem. Bioenerg. 48 (1999) 117.

[9] R. Huang, N. Hu, Biophys. Chem. 104 (2003) 199.

[10] H. Zhou, R. Yang, Y. Xu, K. Han, G. Li, Anal. Lett. 38 (2005) 2103.

[11] K.J. McKenzie, F. Marken, M. Opallo, Bioelectrochemistry 66 (2005) 41

[12] F.A. Armstrong, H.A. Heering, J. Hirsy, Chem. Soc. Rev. 26 (1997) 169.

[13] C. Fan, H. Wang, D. Zhu, G. Wagner, G. Li, Anal. Chem. 73 (2001) 2850.

[14] K. Nam, J. Watanabe, K. Ishihara, Int. J. Pharm. 275 (2004) 259.

[15] T. Wanatabe, A. Ohtsuka, N. Murase, P. Barth, K. Gersonde, Magn. Reson. Med. 35 (1996) 697.

[16] X. Qu, A. Wirsen, A.-C. Albertson, J. Appl. Polym. Sci. 74 (1999) 3186.

[17] C. Wang, R.J. Steward, J. Kopecek, Nature 397 (1999) 417.

[18] M. Collison, E.F. Bowden, M.J. Tralov, Langmuir 8 (1992) 1247.

[19] M. Fedurco, Coord. Chem. Rev. 209 (2000) 263.

[20] K. Miki, T. Ikeda, H. Kinoshita, Electroanalysis 6 (1994) 703

[21] W.R. Hagen, Eur. J. Biochem. 182 (1989) 523.

[22] T. Ozawa, M. Tanaka, Y. Shimomura, Proc. Natl. Acac. Sci. U.S.A. 77 (1980) 5084

[23] R.S. Sirohi, M.A. Gensham, J. Electrochem. Soc. 116 (1969) 910.

[24] H.A. Heering, F.G.M. Wiertz, C. Dekker, S. De Vries, J. Am. Chem. Soc. 126 (2004) 11103.

[25] A.V. Krylov, W. Pfeil, F. Lisdat, J. Electroanal. Chem. 569 (2004) 225.

[26] A. Szúcs, M. Novák, J. Electroanal. Chem. 384 (1995) 47.

[27] F.A. Armstrong, P.A. Cox, H. Allen, O. Hill, V.J. Lowe, B.N. Oliver, J. Electroanal. Chem. 217 (2) (1987) 331.

[28] J. Zhou, X. Lu, J. Hu, J. Li, Chem. Eur. J. 13 (2007) 2847.

[29] D.D. Schlereth, J. Electroanal. Chem. 464 (1999) 198.

[30] M. Noel, K.I. Vasu, Cyclic Voltammetry and the Frontiers of Electrochemistry, Aspect Publications, London, 1990.

[31] K.J. McKenzie, F. Marken, Langmuir 19 (2003) 4327.

[32] A.S. Haas, D.L. Pilloud, K.S. Reddy, G.T. Babcock, C.C. Moser, J.K. Blasie, P.L. Dutton, J. Phys. Chem. 105 (2001) 11351 